\title{
Irregular Pulse
}

National Cancer Institute

\section{Source}

National Cancer Institute. Irregular Pulse. NCI Thesaurus. Code C50622.

Not rhythmic pulse irregular in beat or accent. 